University of Nebraska - Lincoln

DigitalCommons@University of Nebraska - Lincoln

Nebraska Cooperative Fish \& Wildlife Research Nebraska Cooperative Fish \& Wildlife Research Unit -- Staff Publications

$5-2020$

\title{
A Social-Ecological Odyssey in Fisheries and Wildlife Management
}

\author{
Andrew K. Carlson \\ Princeton University, andrewkc@princeton.edu \\ William W. Taylor \\ Michigan State University, taylorw@msu.edu \\ Melissa R. Cronin \\ University of California, Santa Cruz, mecronin@ucsc.edu \\ Mitchell J. Eaton \\ U.S. Geological Survey, meaton@usgs.gov \\ Mark A. Kaemingk \\ University of Nebraska - Lincoln, mkaemingk2@unl.edu
}

See next page for additional authors

Follow this and additional works at: https://digitalcommons.unl.edu/ncfwrustaff

Part of the Aquaculture and Fisheries Commons, Environmental Indicators and Impact Assessment Commons, Environmental Monitoring Commons, Natural Resource Economics Commons, Natural

Resources and Conservation Commons, and the Water Resource Management Commons

Carlson, Andrew K.; Taylor, William W.; Cronin, Melissa R.; Eaton, Mitchell J.; Kaemingk, Mark A.; Reid, Andrea J.; and Trudeau, Ashley, "A Social-Ecological Odyssey in Fisheries and Wildlife Management" (2020). Nebraska Cooperative Fish \& Wildlife Research Unit -- Staff Publications. 296.

https://digitalcommons.unl.edu/ncfwrustaff/296

This Article is brought to you for free and open access by the Nebraska Cooperative Fish \& Wildlife Research Unit at DigitalCommons@University of Nebraska - Lincoln. It has been accepted for inclusion in Nebraska Cooperative Fish \& Wildlife Research Unit -- Staff Publications by an authorized administrator of DigitalCommons@University of Nebraska - Lincoln. 
Authors

Andrew K. Carlson, William W. Taylor, Melissa R. Cronin, Mitchell J. Eaton, Mark A. Kaemingk, Andrea J. Reid, and Ashley Trudeau 


\section{A Social-Ecological Odyssey in Fisheries and Wildlife Management}

Andrew K. Carlson iD | Princeton University, Princeton Environmental Institute, M30 Guyot Hall, Princeton, NJ 08544. E-mail: andrewkc@princeton.edu

William W. Taylor | Michigan State University, Center for Systems Integration and Sustainability, Department of Fisheries and Wildlife, East Lansing, MI

Melissa R. Cronin | University of California, Santa Cruz, Department of Ecology and Evolutionary Biology, Santa Cruz, CA

Mitchell J. Eaton (iD | U.S. Geological Survey, Southeast Climate Adaptation Science Center, North Carolina State University, Raleigh, NC

Lauren E. Eckert | University of Victoria, Department of Geography, Victoria, BC, Canada

Mark A. Kaemingk iD | University of Nebraska-Lincoln, Nebraska Cooperative Fish and Wildlife Research Unit, and School of Natural Resources, Lincoln, NE

Andrea J. Reid | Carleton University, Fish Ecology and Conservation Physiology Laboratory, Department of Biology, Ottawa, ON, Canada

Ashley Trudeau iD | Rutgers University, Graduate Program in Ecology and Evolution, Department of Marine and Coastal Sciences, New Brunswick, NJ

Aldo Leopold, famous ecologist and "father" of North American wildlife management, once said, "These are two things that interest me: the relation of people to each other, and the relation of people to land" (Leopold 1947). Ever prescient, Leopold recognized that natural resource management is fundamentally about humans and their relationship with nature well before conservation became an established way of thinking, much less the bedrock of entire professions. Similarly, amid the Green Revolution to increase agricultural production, in part, through widespread use of pesticides, renowned environmentalist and journalist Rachel Carson noted that we are all "a part of nature, and [our] war against nature is inevitably a war against [ourselves]" (Carson 1962). Leopold's and Carson's words spoke volumes about pressing problems facing humanity and ecosystems at a time when innovative social-ecological thinking in mainstream spheres was direly needed.

Throughout their lives, Leopold and Carson illustrated, in word and deed, how people and the environment are intertwined in ways that affect the productivity and sustainability of human and natural systems. Today, these humanenvironmental connections are well known by some groups of people - thanks to dedicated natural resource scientists, managers, and communicators, not to mention millennia-old connections to and understandings of the land by Indigenous peoples - but are too often unrecognized or taken for granted in broader society. The consequence of such social-ecological silence is a modern natural resource policy management environment that tends to approach conservation in fragments as opposed to holistically across human/social systems (e.g., socioeconomic, political, cultural) and natural/ecological systems (e.g., biological, geological, climatological). Although such fragmentation results from the historical independence of social and natural sciences, as well as the difficulty of integrating them (Liu et al. 2007a, 2007b; Ostrom 2009), we now have the knowledge and tools to write a new social-ecological chapter in conservation history. This is a crucial task because many of the world's most pressing environmental challengesthose that threaten ecosystems and human systems alike (e.g., climate change, biodiversity loss, air and water pollution, food and nutrition insecurity, water scarcity) - are social-ecological by origin and structure, demanding integrative solutions rooted in human-environmental inquiry. Fortunately, the interconnectedness of humans and nature that so fascinated Leopold, Carson, and countless others represents an expanding research area-coupled human and natural systems (CHANS) - with promising potential to improve ecosystem integrity and human health and wellbeing (Hulina et al. 2017; López-Hoffman et al. 2017a; Kaemingk et al. 2020).

Introduced in 2007, the concept and framework of CHANS has made a significant impact in theoretical and fisheries/wildlife management literature (Liu et al. 2007a, 2007b; LópezHoffman et al. 2017b; Carlson et al. 2018, 2019). Building on related approaches (e.g., human-environment systems, complex adaptive systems), the science of CHANS emphasizes linkages (positive and negative) between human and natural systems, as well as attendant complexities (e.g., feedbacks, cross-scalar interactions, legacy effects) that influence their productivity and sustainability. Fisheries and wildlife provide excellent examples of CHANS, wherein humans interact with nature, and nature influences humans, in numerous and intricate ways. For instance, the globally important fishery for Peruvian Anchoveta Engraulis ringens collapsed in 1972 due to overfishing and climate anomalies, leading agricultural producers to expand markets for soy-based (rather than fishbased) poultry feeds in traditionally wheat-producing nations like the USA. As a result, wheat-importing nations such as China, Egypt, Indonesia, and the Soviet Union experienced unexpected food security concerns (Orlic 2011; Carlson et al. 2018). Similarly, as timber harvesting and fuelwood collection increased within Wolong Nature Reserve in China in the 1980s and 1990s, natural habitats for giant panda Ailuropoda melanoleuca became fragmented, decreasing tourism in the nature reserve and thereby reducing direct income for local residents 
(Liu 2017). In addition, income for residents and panda conservation programs declined indirectly via reductions in panda loans to zoos throughout the world, which carry annual fees as high as US\$1 million per panda (Liu 2017).

At the Joint Conference of the American Fisheries Society (AFS) and The Wildlife Society (TWS) in Reno, Nevada (September 29-October 3, 2019), we held a symposium exploring the origins, present conditions, and future directions of CHANS science as applied to fisheries and wildlife. Leveraging our wide-ranging backgrounds (e.g., fisheries, wildlife, social, ecological) across 12 oral presentations, we identified how CHANS has evolved from a largely theoretical field to an applied discipline focused on improving natural resource management. We traced the historical development of fisheries and wildlife management from fields focused primarily on producing fish and game and preventing resource overexploitation by humans - the "dark ages" (Larkin 1988) - to the more socially and ecologically holistic disciplines they are now. We also illustrated benefits of management-focused CHANS research for dozens of symposium attendees throughout the 1-day event. For example, studying fisheries as CHANS has facilitated creative ways to understand these systems, including social-ecological catchments (Martin et al. 2015; Kaemingk et al. 2020): spatial networks of anglers and waterbodies that offer unique fisheries management insights, such as where to hold public meetings and where to focus stocking and habitat rehabilitation activities. Likewise, proposed research in Central African flooded forests intends to build on past studies (Poulsen et al. 2008; Eaton et al. 2009; Eaton 2010; Shirley et al. 2019) by applying CHANS methods to better understand complex predator-prey and food web interactions among resource-dependent humans, an apex predator (African dwarf crocodile Osteolaemus tetraspis), and a diverse forest fishery as human populations grow and climate change intensifies. This CHANS research recognizes that governance influences resource management success or failure (Pahl-Wostl 2009) and considers the role of cultural norms and institutions, local knowledge, social learning, and decision theory in promoting novel governance approaches that diversify livelihood strategies and enhance resource sustainability (Johnson et al. 2015).

In addition to diverse oral presentations and a holistic production-management-governance lens, success of the AFS-TWS symposium hinged on recognizing that CHANS thinking (i.e., integrating human and natural perspectives) predated formal treatment of CHANS in the scientific literature. For instance, "Two-Eyed Seeing" (or Etuaptmumk in Mi'kmaw) is a useful framework for bridging Indigenous and western knowledges and ways of knowing (Bartlett et al. 2012). Originating in the Unama'ki (Cape Breton Island) region of Nova Scotia, Canada, Two-Eyed Seeing was formalized in the literature in 2004 by Mi'kmaw Elder Albert Marshall, but existed in practice in Unama'ki territory, and in diverse forms globally, for millennia prior. A Two-Eyed Seeing framework leverages Indigenous understandings of "the gift of multiple perspectives" in the Mi'kmaw language to build holistic knowledge of natural resources in diverse contexts (e.g., fisheries, forestry, mining, medicine; Bartlett et al. 2012; Denny and Fanning 2016). Today, Two-Eyed Seeing is often co-developed, co-run, and co-evaluated by groups with diverse knowledge systems, legal systems, cultures, viewpoints, and formal educational backgrounds. It relies upon collaborations among involved parties and recognizes that their diverse knowledge and practice systems are equally valid for increasing understanding of complex social-ecological systems (e.g., Mantyka-Pringle et al. 2017). Two-Eyed Seeing and other Indigenous ways of knowing promote application of collaboratively generated research findings into effective CHANS-based resource management and equitable governance strategies. By simultaneously leveraging Indigenous worldviews and those of western science, these approaches are important tools for studying and managing humannature interactions, feedbacks, and other CHANS complexities. Understanding mechanisms whereby Two-Eyed Seeing and related ways of knowing enhance fisheries/wildlife ecology and management - particularly through creation of ecologically effective approaches that are also inclusive and equitable for diverse stakeholders - is an exciting area for advancement of CHANS science and practice.

Using CHANS research to characterize resource-user complexity and thereby enhance fisheries and wildlife management was another focal area of the AFS-TWS symposium. For example, recent work has revealed a linkage between an angler's fish harvest propensity and their residence (Kaemingk et al. 2020), making it important to measure how the spatial distribution of anglers that use a particular waterbody (e.g., size and shape) changes within and across networks of different waterbodies. Fisheries management agencies are currently discussing how these networks-social-ecological catchments - can be used to evaluate the effectiveness of generalized versus area-specific management actions (e.g., harvest regulations), predict the spread of invasive species, and potentially recruit new anglers. Other examples of complex, management-relevant angler behaviors include anglers' attraction to overexploited, often low-catch sites due to their unique attributes (e.g., convenience, aesthetics, emotional connections; Johnston et al. 2010) and hyperstability of catch rates, whereby anglers continue fishing in particular locations despite declining fish abundance (Hansen et al. 2005). Overall, a "grand challenge" in fisheries science and management is quantifying how angler behaviors interact with waterbody morphometry (Kaemingk et al. 2019) and landscape variables (Matsumura et al. 2019) to influence angling effort and ultimately the efficacy of different management strategies. Navigating this challenge through continued CHANS research will provide a portfolio of management approaches tailored to heterogeneous angler populations with different characteristics and motivations, allowing managers to address unique social-ecological conditions within - and connectivity among - waterbodies in fisheries landscapes.

Conceptually, designing fisheries and wildlife management programs to optimize social-ecological conditions within and among individual systems is a powerful example of "the gift of multiple perspectives," much like Two-Eyed Seeing. In practice, understanding and managing fisheries and wildlife systems at local, regional, and global levels is extraordinarily difficult, reflecting the historical independence of social and natural sciences and the intrinsic complexity of human-environmental synthesis (Liu et al. 2007a, 2007b; Ostrom 2009). Fortunately, fisheries and wildlife professionals are developing ways to operationalize the CHANS approach, including the metacoupling and telecoupling frameworks (Liu 2017). The metacoupling framework - an advancement of the telecoupling framework - is a systematic approach for understanding multiscalar human-nature interactions (metacouplings), defined as those occurring between distant CHANS (telecouplings), 


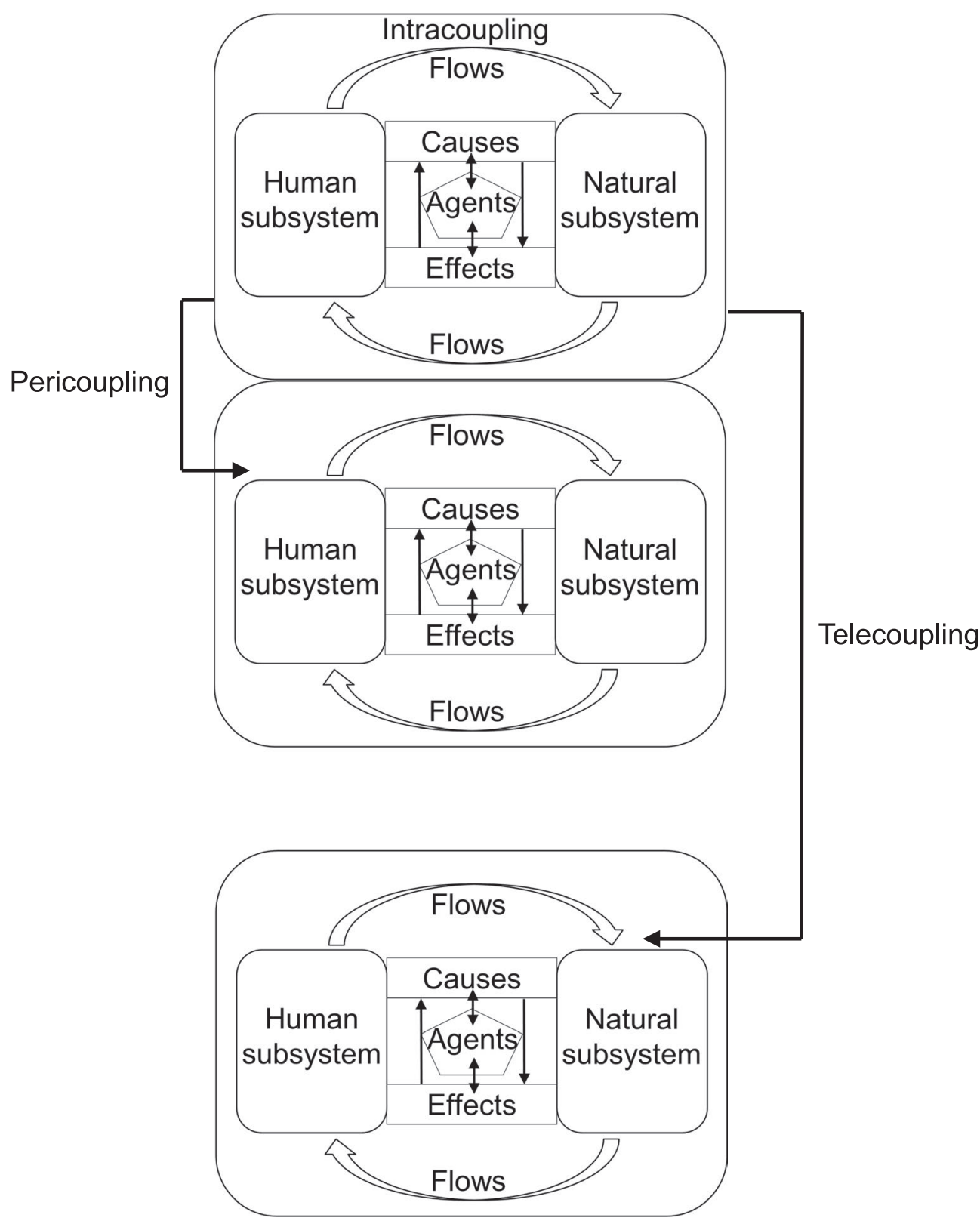

Figure 1. Diagram of metacoupling: social-ecological interactions (arrows) between distant coupled human and natural systems (telecoupling), between adjacent systems (pericoupling), and within a focal system (intracoupling). Flows are movements of animals, money, materials, information, and people within and between systems. Agents are autonomous decision-making entities (e.g., people, organizations, governments) that directly or indirectly facilitate or hinder couplings. Causes are environmental, socioeconomic, political, technological, and cultural factors that influence the emergence or dynamics of couplings. Effects are the impacts and consequences of couplings.

between adjacent CHANS (pericouplings), and within individual CHANS (intracouplings; Figure 1). By breaking these complicated interactions into their constituent systems, flows (e.g., animals, money, materials, information, people), agents (e.g., people, organizations), causes, and effects, the metacoupling framework clarifies how human-nature interactions unfold at local, regional, and global scales (Figure 1).

For instance, marine fishing technologies such as diesel engines, freezer trawlers, and radar spread throughout the world in the early- to mid-20th century, allowing nations to fish beyond their borders and thereby creating telecouplings of technological information, fishers, and fish (via catch and trade). Likewise, collapse of the Peruvian Anchoveta fishery in 1972 affected recognizable global flows, such as fishmeal and fish oil trade and monetary exchange, as well as flows that were less familiar due to a trade-focused philosophy in Peru, including movement of people and international knowledge transfer regarding fisheries sustainability (Carlson et al. 2018). Resultant Anchoveta scarcity caused telecouplings (e.g., reduced wheat availability, global food security concerns), pericouplings (e.g., decreased Anchoveta abundance in Chile due to fishing competition with Peru), and intracouplings such as government reorganization in Peru and implementation of fishery management strategies to prevent future stock collapses (Figure 2). The metacoupling framework also applies to recreational fisheries. For example, Michigan coldwater streams containing 


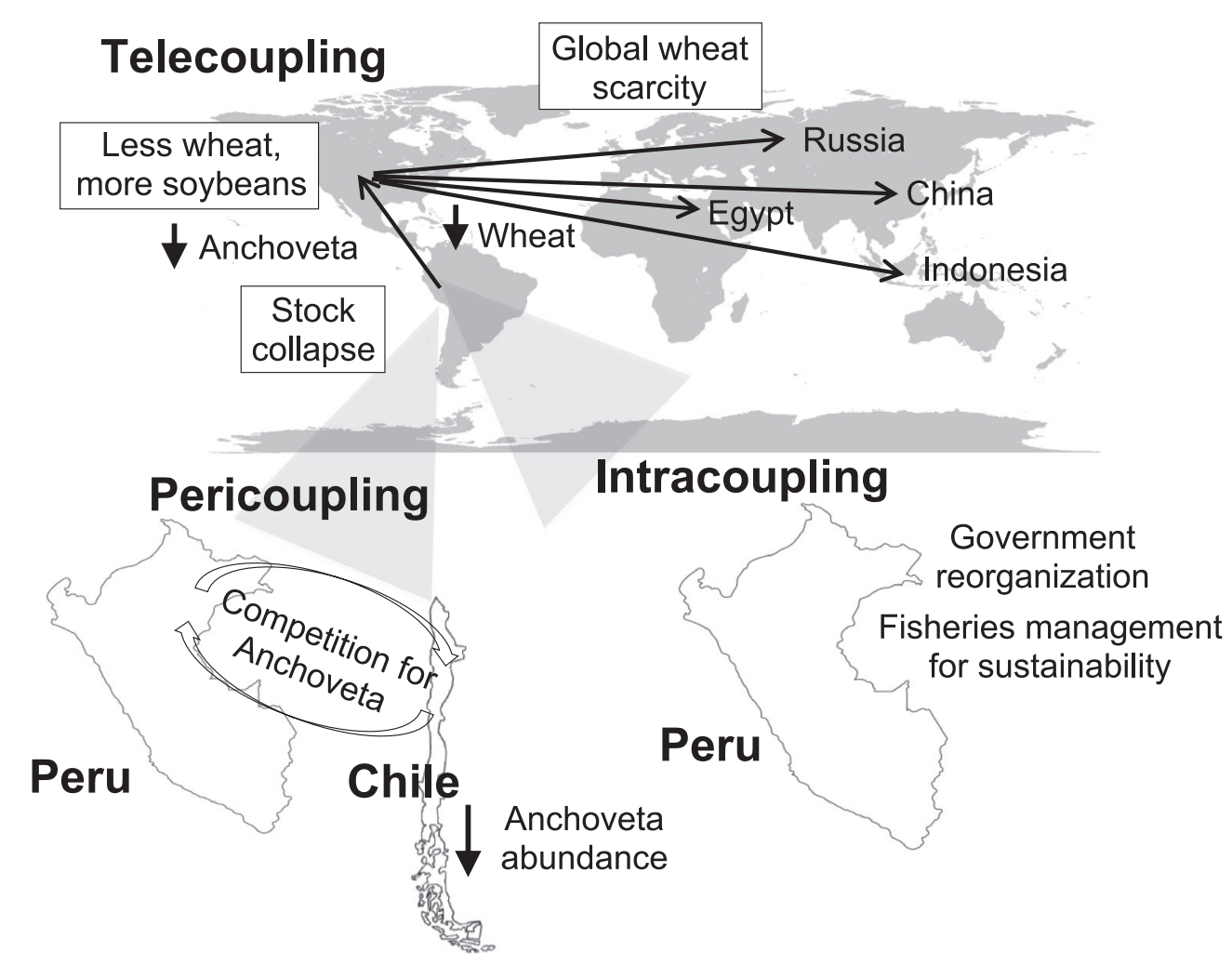

Figure 2. Metacoupling in the Peruvian Anchoveta fishery. After the 1972 stock collapse, flows of Anchoveta to the United States declined, leading farmers to plant less wheat and more soybeans to increase production of soy-based (rather than fish-based) poultry feeds. Effects included telecouplings (global wheat scarcity, food security concerns), pericouplings (reduced Anchoveta abundance in Chile, resulting from fishing competition with Peru), and intracouplings (government reorganization in Peru, emergence of sustainability as a fisheries management paradigm).

Brook Trout Salvelinus fontinalis and Brown Trout Salmo trutta are affected by flows of water, information, fish, people, and money within and between CHANS; these metacouplings provide drinking water, recreational fisheries, and employment for thousands of people locally, regionally, and throughout the state of Michigan. Nestlé water bottling facilities generate county-level contributions (intracouplings) of 284 jobs and \$24.2 million in total economic activity (PSC 2017; Carlson et al. 2020). Contributions in the five-county region (pericouplings) and across Michigan (telecouplings) amount to 634 jobs/\$71.9 million and 1,273 jobs/\$235.0 million, respectively. However, Nestlé's groundwater withdrawal operations alter stream hydrology and cause social consequences, including staunch disapproval of - and protests by - anglers and landowners who experience reduced water levels, trout abundance, and angling quality in streams where groundwater is extracted (Carlson et al. 2020). Overall, recreational fisheries management can be improved by using the metacoupling framework to integrate human and environmental information, evaluate resource-user diversity, and create metacoupling-informed management programs that promote socially and ecologically desirable outcomes across scales.

In addition to recreational fisheries, the metacoupling framework has broader implications for fisheries and wildlife management and governance. Not only is it systematic and logically organized (i.e., systems, flows, agents, causes, effects; Figure 1), the metacoupling framework integrates socialecological data across space and time, a perennially difficult, yet critical task for streamlining natural resource conservation programs. The metacoupling framework also clarifies CHANS complexities (e.g., feedbacks, cross-scalar interactions, legacy effects; Liu 2017) in ways that improve management and governance of terrestrial and aquatic animals, including Kirtland's warbler Setophaga kirtlandii (Hulina et al. 2017), Mexican freetailed bats Tadarida brasiliensis (López-Hoffman et al. 2017a, 2017b), and Great Lakes Chinook Salmon Oncorhynchus tshawytscha and Coho Salmon O. kisutch (Carlson et al. 2019). Moreover, the metacoupling framework advances the notion of metacoupled resource governance, which explicitly accounts for and manages metacouplings across scales to enhance fisheries and wildlife sustainability locally, regionally, and globally. By providing human-environmental insights beyond those generated by monothematic (i.e., social or ecological) approaches (Liu 2017; Schaffer-Smith et al. 2018; Zhao et al. 2018), the metacoupling framework has great potential for advancing fisheries/wildlife research and management. For instance, the framework can be used to understand how social-ecological linkages across spatial scales influence the spread of invasive species and diseases, the effectiveness of public outreach programs, and the complexity of natural resource valuation (monetary and non-monetary). However, the metacoupling framework has limitations (e.g., need for longterm data collected across multiple spatial scales, shortage of quantitative tools) that are best addressed by using the framework in combination with other social-ecological research approaches.

The notion of fisheries and wildlife as CHANS has underpinned historical natural resource management and grown considerably in recent years with advances in the theory and practice of social-ecological integration. Prescience of 
environmental giants like Aldo Leopold and Rachel Carson and contributions of countless fisheries and wildlife professionals have fostered remarkable achievements in the CHANS field, but potential barriers to progress exist. For instance, continued growth of CHANS research and management may be impeded by the inherent difficulty of integrating social and natural sciences that arose independently (Liu et al. 2007a, 2007b; Ostrom 2009). In addition, university curricula generally do not emphasize CHANS science and practice. In a survey of 180 academics (and 27 non-academics) affiliated with the International Network of Research on CHANS, education ranked 10th of 12 categories in terms of importance for the "top 40" questions in CHANS research, placing it well behind categories such as land-use change, climate change, and sustainable development (Kramer et al. 2017). Only two education-related questions made the top 40; neither focused on training the next generation of CHANS scientists, much less updating university curricula to encompass CHANS. Given the high percentage of academic respondents, it appears that educational dimensions of CHANS are less prioritized at universities than other important topics, perhaps reflecting broader obstacles to interdisciplinarity in academia. For example, it is understandably difficult for universities to create CHANS-focused learning and research environments amid resource limitations and lengthy start-up times for interdisciplinary programs, departmentally focused academic reward systems, and cross-departmental differences in terminology (e.g., "proof," "precision") and divergent opinions about the need for interdisciplinarity (NAS 2005; Rasmussen and Arler 2010; Cooke et al. 2020).

We imagine a world where CHANS is a widely recognized concept and a pedagogical keystone like mitosis or food webs. Essential in this world are CHANS education and outreach programs that familiarize people with multifaceted linkages among natural and social sciences, including ecology, fisheries/wildlife management, economics, political science, psychology, sociology, and decision science. Universities are uniquely positioned to foster societal understanding of these connections. However, CHANS education cannot be limited to fisheries and wildlife professionals - farmers, politicians, political appointees in conservation agencies, and indeed all spheres of society must be empowered to understand the importance of CHANS as a unifying concept across professions and lives. Anything less will cause important segments of society to remain unfamiliar with CHANS or unequipped to collaborate with natural resource professionals, with the consequence that conservation will be practiced in fragmentary fashion, rather than holistically across coupled systems. Likewise, other social-ecological challenges threatening ecosystems and human systems (e.g., climate change, food/nutrition insecurity, water scarcity) will remain only partially resolvable, at best.

In our experience, interdisciplinary events such as CHANS symposia are valuable for facilitating syntheses and synergies (e.g., social-ecological, fisheries/wildlife) that advance CHANS education, research, and resource management. Symposia and other knowledge exchange fora should include people representing diverse identities and disciplinary backgrounds, offer repeated opportunities for interdisciplinary discussion and idea formation, and capitalize on cross-disciplinary benefits of large conferences like the AFS-TWS meeting (e.g., collaborative workspaces, networking events, plenary sessions). We also recommend concluding interdisciplinary fora with panel discussions, collaborative manuscripts, and related activities that tangibly advance CHANS knowledge. Such advancements can provide answers to pressing questions in fisheries/wildlife research and management, including how social-ecological interactions influence the success of population augmentation and habitat rehabilitation initiatives, the efficacy of public outreach campaigns, the effectiveness of climate-adaptive resource management, and other important elements of conservation (Johnson et al. 2015; Denny and Fanning 2016; Hulina et al. 2017; Carlson et al. 2019, 2020). Overall, substantial strides in CHANS science and management in recent years have exposed deeper, more complex, and more interdisciplinary challenges than those originally imagined. The social-ecological odyssey continues.

There is no conflict of interest declared in this article.

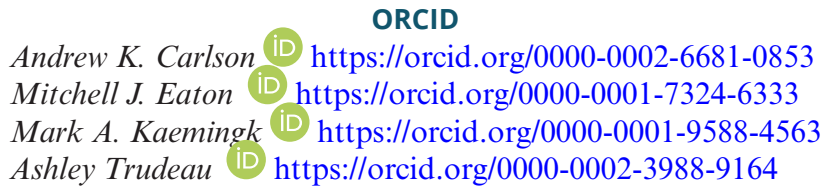

\section{REFERENCES}

Bartlett, C., M. Marshall, and A. Marshall. 2012. Two-Eyed Seeing and other lessons learned within a co-learning journey of bringing together indigenous and mainstream knowledges and ways of knowing. Journal of Environmental Studies and Sciences 2:331-340.

Carlson, A. K., W. W. Taylor, and S. M. Hughes. 2020. The metacoupling framework informs stream salmonid management and governance. Frontiers in Environmental Science 8:27.

Carlson, A. K., W. W. Taylor, and J. Liu. 2019. Using the telecoupling framework to improve Great Lakes fisheries sustainability. Aquatic Ecosystem Health \& Management 22:342-354.

Carlson, A. K., W. W. Taylor, J. Liu, and I. Orlic. 2018. Peruvian Anchoveta as a telecoupled fisheries system. Ecology and Society 23:35.

Carson, R. 1962. Silent spring. Houghton Mifflin, Boston.

Cooke, S. J., V. M. Nguyen, D. Anastakis, S. D. Scott, M. R. Turetsky, A. Amirfazli, A. Hearn, C. E. Milton, L. Loewen, E. E. Smith, D. R. Norris, K. L. Lavoie, A. Aiken, D. Ansari, A. N. Antle, M. Babel, J. Bailey, D. M. Bernstein, R. Birnbaum, C. Bourassa, A. Calcagno, A. Campana, B. Chen, K. Collins, C. E. Connelly, M. Denov, B. Dupont, E. George, I. Gregory-Eaves, S. High, J. M. Hill, P. L. Jackson, N. Jette, M. Jurdjevic, A. Kothari, P. Khairy, S. A. Lamoureux, K. Ladner, C. R. Landry, F. Légaré, N. Lehoux, C. Leuprecht, A. R. Lieverse, A. Luczak, M. L. Mallory, E. Manning, A. Mazalek, S. J. Murray, L. L. Newman, V. Oosterveld, P. Potvin, S. Reimer-Kirkham, J. Rowsell, D. Stacey, S. L. Tighe, D. J. Vocadlo, A. E. Wilson, and A. Woolford. 2020. Diverse perspectives on interdisciplinarity from members of the College of the Royal Society of Canada. FACETS 5:138-165.

Denny, S. K., and L. M. Fanning. 2016. A Mi'kmaw perspective on advancing salmon governance in Nova Scotia, Canada: setting the stage for collaborative co-existence. International Indigenous Policy Journal 7:1-25.

Eaton, M. J. 2010. Long-term monitoring and management of wildlife resources in the Lac Tele Community Reserve (LTCR), Republic of Congo: fisheries, bushmeat and crocodiles. Report to the Rufford Foundation, London.

Eaton, M. J., A. Martin, J. B. Thorbjarnarson, and G.Amato. 2009. Specieslevel diversification of African dwarf crocodiles (Genus Osteolaemus): a geographic and molecular phylogenetic perspective. Molecular Phylogenetics and Evolution 50:496-506.

Hansen, M. J., T. D. Beard Jr., and S. W. Hewett. 2005. Effect of measurement error on tests of density dependence of catchability for Walleyes in northern Wisconsin angling and spearing fisheries. North American Journal of Fisheries Management 25: 1010-1015.

Hulina, J., C. Bocetti, H. Campa III, V. Hull, W. Yang, and J. Liu. 2017. Telecoupling framework for research on migratory species in the Anthropocene. Elementa: Science of the Anthropocene 5:5. 
Johnson, F. A., G. S. Boomer, B. K. Williams, J. D. Nichols, and D. J. Case. 2015. Multilevel learning in the adaptive management of waterfowl harvests: 20 years and counting. Wildlife Society Bulletin 39:9-19.

Johnston, F. D., R. Arlinghaus, and U. Dieckmann. 2010. Diversity and complexity of angler behaviour drive socially optimal input and output regulations in a bioeconomic recreational-fisheries model. Canadian Journal of Fisheries and Aquatic Sciences 67:1507-1531.

Kaemingk, M. A., C. J. Chizinski, C. R. Allen, and K. L. Pope. 2019. Ecosystem size predicts social-ecological dynamics. Ecology and Society 24:17.

Kaemingk, M. A., K. L. Hurley, C. J. Chizinski, and K. L. Pope. 2020. Harvestrelease decisions in recreational fisheries. Canadian Journal of Fisheries and Aquatic Sciences 77:194-201.

Kramer, D. B., J. Hartter, A. E. Boag, M. Jain, K. Stevens, K. A. Nicholas, W. J. McConnell, and J. Liu. 2017. Top 40 questions in coupled human and natural systems (CHANS) research. Ecology and Society 22:44.

Larkin, P. A. 1988. The future of fisheries management-managing the fisherman. Fisheries 13(1):3-9.

Leopold, A. 1947. Wherefore wildlife ecology? Pages 336-337 in S. L. Flader, and J. B. Callicott, editors. The river of the mother of god and other essays by Aldo Leopold. University of Wisconsin Press, Madison.

Liu, J. 2017. Integration across a metacoupled world. Ecology and Society 22:29.

Liu, J., T. Dietz, S. R. Carpenter, M. Alberti, C. Folke, E. Moran, A. N Pell, P. Deadman, T. Kratz, J. Lubchenco, E. Ostrom, Z. Ouyang, W. Provencher, C. L. Redman, S. H. Schneider, and W. W. Taylor. 2007b. Complexity of coupled human and natural systems. Science 317:1513-1516

Liu, J., T. Dietz, S. R. Carpenter, C. Folke, M. Alberti, C. L. Redman, S. H. Schneider, E. Ostrom, A. N. Pell, J. Lubchenco, W. W. Taylor, Z. Ouyang, P. Deadman, T. Kratz, and W. Provencher. 2007a. Coupled human and natural systems. Ambio 36:639-649.

López-Hoffman, L., C. C. Chester, D. J. Semmens, W. E. Thogmartin M. Sofia Rodríguez-McGoffin, R. Merideth, and J. E. Diffendorfer. 2017a. Ecosystem services from transboundary migratory species: Implications for conservation governance. Annual Review of Environment and Resources 42:509-539.

López-Hoffman, L., J. Diffendorfer, R. Wiederholt, K. J. Bagstad, W. E. Thogmartin, G. McCracken, R. L. Medellin, A. Russel, and D. J. Semmens. 2017b. Operationalizing the telecoupling framework for migratory species using the spatial subsidies approach to examine ecosystem services provided by Mexican free-tailed bats. Ecology and Society 22:23.

Mantyka-Pringle, C. S., T. D. Jardine, L. Bradford, L. Bharadwaj, A. P. Kythreotis, J. Fresque-Baxter, E. Kelly, G. Somers, L. E. Doig, P. D. Jones, K.-E. Lindenschmidt, and the Slave River and Delta Partnership. 2017. Bridging science and traditional knowledge to assess cumulative impacts of stressors on ecosystem health. Environment International 102:125-137.

Martin, D. R. C. J. Chizinski, and K. L. Pope. 2015. Reservoir area of influence and implications for fisheries management. North American Journal of Fisheries Management 35:185-190.

Matsumura, S., B. Beardmore, W. Haider, U. Dieckmann, and R. Arlinghaus. 2019. Ecological, angler, and spatial heterogeneity drive social and ecological outcomes in an integrated landscape model of freshwater recreational fisheries. Reviews in Fisheries Science and Aquaculture 27:170-197.

NAS (National Academy of Sciences). 2005. Facilitating interdisciplinary research. National Academy of Sciences, National Academy of Engineering, and Institute of Medicine. The National Academies Press, Washington, D.C.

Orlic, I. 2011. Innovation, leadership, and management of the Peruvian Anchoveta fishery: approaching sustainability. Pages 145-183 in W. W. Taylor, A. J. Lynch and M. G. Schechter, editors. Sustainable fisheries: multi-level approaches to a global problem. American Fisheries Society, Bethesda, Maryland.
Ostrom, E. 2009. A general framework for analyzing sustainability of social-ecological systems. Science 325:419-422.

Pahl-Wostl, C. 2009. A conceptual framework for analysing adaptive capacity and multi-level learning processes in resource governance regimes. Global Environmental Change 19:354-365.

Poulsen, J. R., C. J. Clark, and G. A. Mavah. 2008. Wildlife management in a logging concession in Northern Congo: can livelihoods be maintained through sustainable hunting? Pages 140-157 in G. L. Davies and D. Brown, editors. Bushmeat and livelihoods: wildlife management and poverty reduction. Blackwell Publishing, Oxford, UK.

PSC (Public Sector Consultants). 2017. Economic contribution of NWNA to Michigan: statewide, regional, and local contribution. PSC, Lansing, Michigan.

Rasmussen, K., and F. Arler. 2010. Interdisciplinarity at the humanenvironment interface. Geografisk Tidsskrift-Danish Journal of Geography 110:37-45.

Schaffer-Smith, D., S. A. Tomscha, K. J. Jarvis, D. Y. Maguire, M. L. Treglia, and J. Liu. 2018. Network analysis as a tool for quantifying the dynamics of metacoupled systems: an example using global soybean trade. Ecology and Society 23:3.

Shirley, M. H., B. J. Evans, B. Madzoke, G. Bondeko, and R. Mobongo. 2019. Sustainable management of the Lac Tele dwarf crocodile fishery: laying the foundation for future action. Report to the Wildlife Conservation Society, New York.

Zhao, W., Y. Liu, S. Daryanto, B. Fu, S. Wang, and Y. Liu. 2018. Metacoupling supply and demand for soil conservation service. Current Opinion in Environmental Sustainability 2018:136-141. AFS 